\title{
CUTOFF VALUE OF TWO-POINT DISCRIMINATION DISTANCES IN CARPAL TUNNEL SYNDROME
}

Chanasak Hathaiareerug *, Piyawa Ngamongard **, Thong Phonghanyudh *

* Department of Physical Medicine and Rehabilitation, Phramongkutklao Hospital, Bangkok, Thailand

** Department of Physical Medicine and Rehabilitation, Hospital for Tropical Diseases, Mahidol University, Bangkok, Thailand

\begin{abstract}
Background: Two-point discrimination test (2PD) represents large sensor fiber, which is more sensitive than smaller fiber to detect abnormality in carpal tunnel syndrome (CTS). Few studies have focused in 2PD to diagnose CTS.
\end{abstract}

Objective: The study aimed to establish the cutoff value of 2PD to determine CTS.

Methods: A descriptive diagnostic study was conducted at the Outpatient Department of Rehabilitation Medicine, Phramongkutklao Hospital. Participants who were suspected of having CTS were included in the study. All participants performed the 2PD test at the thumb, index finger and middle finger. The nerve conduction studies were performed and definitive diagnosis of CTS was based on the results. Data were analyzed using the receiver operation coefficient curve.

Results: Of 48 participants (total of 95 hands), CTS was diagnosed in 85 hands (89.5\%). Additionally, of all CTS hands, severity was mild degree in 17 hands (28.4\%), moderate degree in 31 hands $(32.6 \%)$ and severe degree in 37 hands (39\%). The optimum cutoff values were $>4 \mathrm{~mm}$ having the sensitivities of $75.3,68.2$ and $68.2 \%$ while the specificities were 80,90 and $90 \%$, respectively, for the thumb, index finger and middle finger. The areas under curve were $0.826,0.833$ and 0.823 , respectively.

Conclusion: The participants with more than $4 \mathrm{~mm}$ of 2PD at the thumb, index finger and middle finger had high probability of having CTS.

Keywords: Two-point discrimination test, Carpal tunnel syndrome, Sensory testing

J Southeast Asian Med Res 2020; 4(1): 1-6

http://www.jseamed.org

Correspondence to:

Hathaiareerug C., Department of Physical Medicine and Rehabilitation, Phramongkutklao Hospital, Bangkok, Thailand

E-mail : chanasak.h@pcm.ac.th

Received: 3 August 2019

Revised: 15 February 2020

Accepted: 12 May 2020 


\section{Introduction}

Carpal tunnel syndrome (CTS) is the most common entrapment neuropathy. ${ }^{(1,2)}$ Classic clinical characteristics of CTS include numbness and tingling along the median sensory distribution and weakness or atrophy of the thenar muscle. Most patients reported nocturnal pain. Diagnosis of CTS involves a combination of several physical examinations and electrophysiological data obtained from nerve conduction study (NCS) of the median nerve. ${ }^{(3-6)} \mathrm{NCS}$ provides excellent validity and reliability and is accepted as the gold standard for diagnosing CTS. ${ }^{(7-9)}$

Most patients report sensory symptoms in early stage of $\mathrm{CTS}^{(6)}$ Larger sensory fiber is more sensitive than smaller fiber to detect abnormality. ${ }^{(10)}$ Two-point discrimination (2PD) is the most widely-used and reliable test. ${ }^{(11,12)}$ Despite many studies evaluating the validity and reliability of 2PD, the cutoff point to diagnose CTS using this pragmatic test remains unclear. ${ }^{(13-18)}$ This study aimed to establish the cutoff value of the 2PD test to determine CTS.

\section{Methods \\ Population}

This study recruited Thai patients who were suspected of having CTS and were sent to the Rehabilitation Department, Phramongkutklao Hospital. Eligible patients aged 20 to 80 years having at least one of the following signs and symptoms were recruited in the study: ${ }^{(19)}$ 1) numbness or tingling of the hand(s) at rest, 2) numbness or tingling sensation of the hand(s) during light activity, 3) flicking of the hand(s) that improves numbness or tingling or 4) weakness of the hand(s). Participants, receiving a diagnosis of peripheral neuropathy, experiencing altered consciousness, cervical radiculopathy or rheumatic diseasesincluding bone fracture, steroid injection or hand(s) surgery, were excluded. Participants signed consent forms to participate in the study. The study protocol was approved by the Institutional Review Board of the Royal Thai Army Medical Department (IRBRTA 016/2560).

\section{Sample size determination}

The sample size was calculated based on the sensitivity and prevalence from the study of Ziswiler HR. et al, ${ }^{(20)}$ and MacDermid JC. et al. ${ }^{(16,17)}$ The sample size totaled 92 hands with suspected CTS to provide $5 \%$ type-I error and $10 \%$ type-II error.

\section{Two-Point Discrimination}

Basic characteristic datawere obtained. Patients were asked to sit relaxed and place the affected hand on the bed. After closing their eyes, the Touch Test ${ }^{\circledR}$ Two-point discriminator (Figure 1) was used set perpendicular to the tip of the thumb, index and middle fingers. The examiner started with $2 \mathrm{~mm}$ and increased by $1 \mathrm{~mm}$ until patients discriminated 2 points and recorded the distance. ${ }^{(21)}$ An intraining physiatrist resident obtained all basic characteristic data and the 2PD test. The 2PD test was conducted before performing the nerve conduction study.

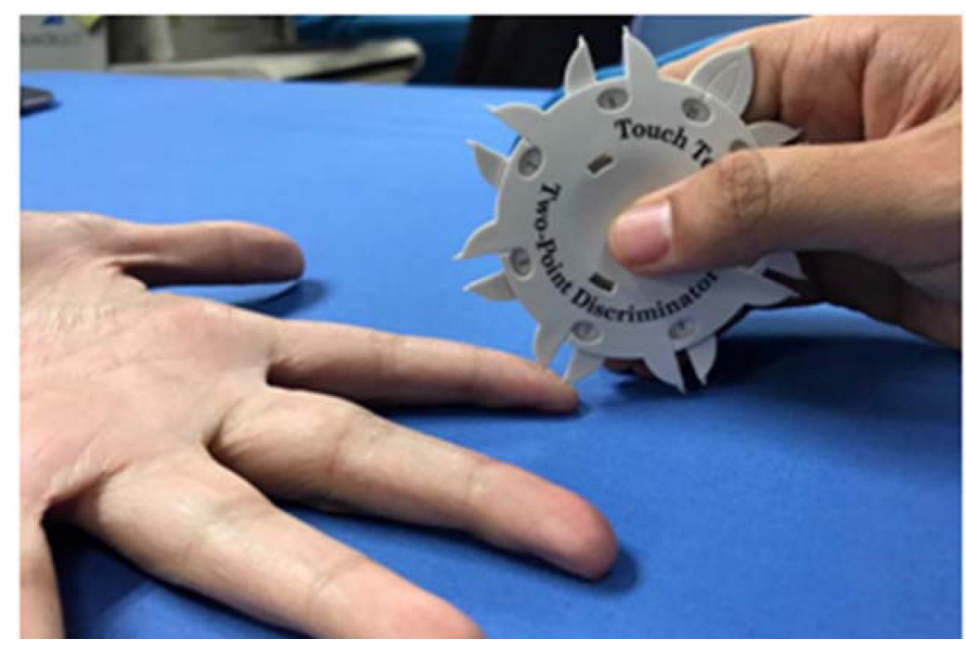

Figure 1. Touch Test ${ }^{\circledR}$ Two-point discriminator 
Table 1. Electrodiagnosis classification of CTS

\begin{tabular}{lllll}
\hline & no CTS & Mild CTS & Moderate CTS & Severe CTS \\
\hline sensory latency & normal & prolonged & prolonged & prolonged or absent \\
sensory amplitude & normal & normal & normal & low or absent \\
motor latency & normal & normal & prolonged & prolonged or absent \\
motor amplitude & normal & normal & normal & low or absent \\
\hline
\end{tabular}

Table 2. Sensitivity, specificity, and predictive value of each cutoff value of the thumb

\begin{tabular}{|c|c|c|c|c|c|c|}
\hline Criterion (mm) & Sensitivity & $95 \% \mathrm{CI}$ & Specificity & $95 \% \mathrm{CI}$ & PPV & NPV \\
\hline \multicolumn{7}{|l|}{ Thumb } \\
\hline$>2$ & 97.65 & $91.8-99.7$ & 10 & $0.3-44.5$ & 90.2 & 33 \\
\hline$>3$ & 89.41 & $80.8-95.0$ & 30 & $6.7-65.2$ & 91.6 & 25 \\
\hline$>4$ & 75.29 & $64.7-84.0$ & 80 & $44.4-97.5$ & 97 & 27 \\
\hline$>5$ & 55.29 & $44.1-66.1$ & 100 & $69.2-100.0$ & 100 & 20.8 \\
\hline$>13$ & 0 & $0.0-4.2$ & 100 & $69.2-100.0$ & & 10.5 \\
\hline \multicolumn{7}{|l|}{ Index finger } \\
\hline$>2$ & 96.47 & $90.0-99.3$ & 10 & $0.3-44.5$ & 90.1 & 25 \\
\hline$>3$ & 83.53 & $73.9-90.7$ & 70 & $34.8-93.3$ & 95.9 & 33 \\
\hline$>4$ & 68.24 & $57.2-77.9$ & 90 & $55.5-99.7$ & 98.3 & 25 \\
\hline$>5$ & 51.76 & $40.7-62.7$ & 90 & $55.5-99.7$ & 97.8 & 18 \\
\hline$>6$ & 36.47 & $26.3-47.6$ & 100 & $69.2-100.0$ & 100.0 & 15.6 \\
\hline$>13$ & 0 & $0.0-4.2$ & 100 & $69.2-100.0$ & & 10.5 \\
\hline \multicolumn{7}{|l|}{ Middle finger } \\
\hline$>2$ & 95.29 & $88.4-98.7$ & 0 & $0.0-30.8$ & 89 & 0 \\
\hline$>3$ & 83.53 & $73.9-90.7$ & 60 & $26.2-87.8$ & 94.7 & 30 \\
\hline$>4$ & 68.24 & $57.2-77.9$ & 90 & $55.5-99.7$ & 98.3 & 25 \\
\hline$>5$ & 52.94 & $41.8-63.9$ & 100 & $69.2-100.0$ & 100.0 & 20 \\
\hline$>14$ & 0 & $0.0-4.2$ & 100 & $69.2-100.0$ & & 10.5 \\
\hline
\end{tabular}



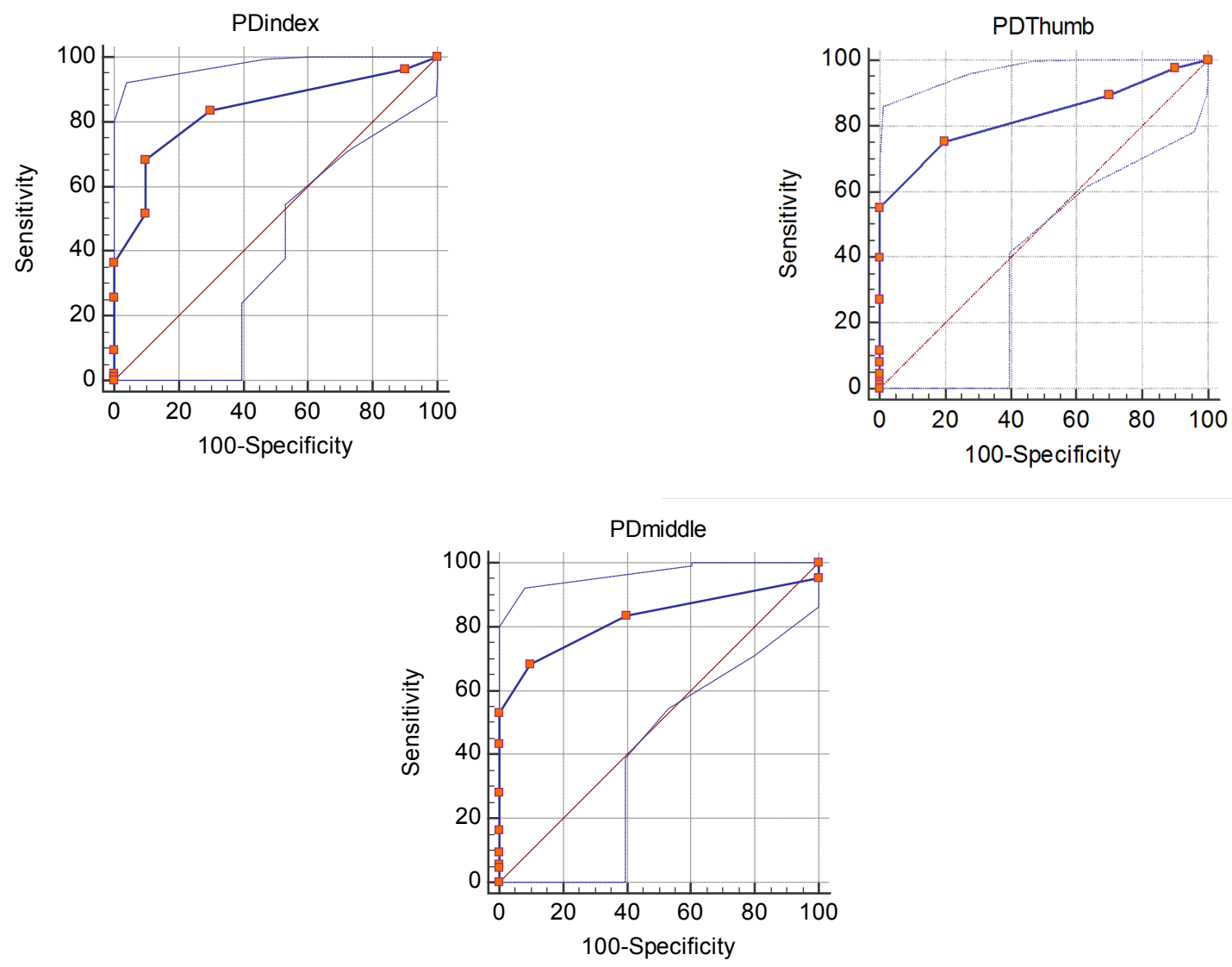

Figure 2. Receiver Operation Coefficient (ROC) curve of the 2PD test of each finger

\section{Nerve conduction studies}

A single physiatrist who was blinded to the 2PD results performed NCS on the same day of 2PD. A standard electrodiagnosis machine (Medelec Synergy T5EP model, Oxford Instruments, Oxfordshire, UK) was used. Sensory NCS was performed at the 14-cm antidromic sensory median and ulnar nerve ${ }^{(22,23)}$ for peak latency and amplitude. Normal values for the median nerve were $3.6 \mathrm{~ms}$ and $10 \mu \mathrm{V}$, respectively. Motor NCS was performed at 8-cm orthodromic median and ulnar nerve to determine distal motor latencies, amplitude and nerve conduction velocity. Normal values were $4.2 \mathrm{~ms}$ and $5 \mathrm{mV}$, respectively. The NCS results were classified in four groups: none, mild, moderate and severe CTS. ${ }^{(24)}$

\section{Statistical analysis}

The overall diagnostic value of $2 \mathrm{PD}$ was evaluated by the area under the receiver operator characteristics (ROC) curve using MedCalc Statistic Software, Version 18.2.1. The data was analyzed for sensitivity, specificity, positive predictive value (PPV), and negative predictive value (NPV) across a range of the 2PD from $2 \mathrm{~mm}$ in $1 \mathrm{~mm}$ incremention. Spearman's rank correlation coefficient was used to assess the relationship between $2 \mathrm{PD}$ and CTS severity.

\section{Results}

The 2PD was positively correlated with severity of CTS with $r=0.48, r=0.51, r=0.49$ in the thumb, index, and middle fingers, respectively. Of the 95 hands (48 participants), most were female $(77.1 \%)$ with mean age of $57.8 \pm 12.2$ years. The number of patients presenting bilateral, left hand and right hand symptoms were 52.1, 29.9 and $25.0 \%$, respectively. Diabetes Mellitus was noted in $16.7 \%$, and CTS was diagnosed in 85 hands (89.47\%). Of all 85 hands with CTS 28.4 (17 hands), 32.6 (31 hands) and 38.9\% (37 hands) were documented as mild, moderate, and severe CTS, respectively. According to the ROC curve, a $>4 \mathrm{~mm} 2 \mathrm{PD}$ could be used as the best cutoff value between the sensitivity and specificity for the thumb $(75.3 \%, 80 \%)$, index $(68.2 \%, 90 \%)$, and middle $(68.2 \%, 90 \%)$ fingers. In addition, $4 \mathrm{~mm}$ cutoff value showed PPV 97 to $98.3 \%$ and NPV 25 to 27\%. (Table 2 and Figure 2) 


\section{Discussion}

The 2PD test and CTS severity exhibited moderate positive correlation. This result correlated with a related study by Elfar et al. (22) who reported $r=0.48$. This is the first study to determine the cutoff value of $2 \mathrm{PD}$ in diagnosing CTS. However, the cutoff value in this prospective study differed from related studies ${ }^{(18,25)}$. Elfar et al. evaluated 2PD in 40 CTS hands and reported a mean $2 \mathrm{PD}$ value of the middle finger as $6.07 \mathrm{~mm}$. Diagnostic value and cutoff point from ROC were not reported in that study. However, race and nationality may have affected the 2PD test result. Regarding nerve injury of the upper extremity, Vorawanthanachai et al. recommended $>4 \mathrm{~mm}$ to diagnose ulnar neuropathy at the elbow. ${ }^{(26)}$ The cutoff value in this study was similar to that of Wolny et al. ${ }^{(27)}$, reporting mean 2PD in the index and middle fingers as $4.75 \pm 1.33$ and $3.83 \pm 0.85$, respectively.

The 2PD test has high sensitivity and specificity. Using $4 \mathrm{~mm}$ cutoff point provided the highest sensitivity $(75.3 \%)$ in the thumb and the greatest specificity in the index and middle fingers $(90 \%)$. These results resembled those of a study of other provocative tests in Thailand. Khanittanuphong reported the modified phalen test had a sensitivity of $70 \%$, and the carpal compression test had a specificity of $85 \%$ to diagnose CTS. ${ }^{(28)}$

The 2PD test could be used in addition to standard physical examination to diagnose CTS because this test did not provoke uncomfortable symptoms in patients. However, the 2PD test was unable to grade severity of CTS.

Interestingly, the 2PD at the index finger increased the sensitivity to $83.5 \%$ but the specificity reduced to $70 \%$ when the cutoff point changed to $3 \mathrm{~mm}$. The sensitivity and specificity of $3 \mathrm{~mm}$ had more power to rule out CTS.

A review article published by Macdermid et al. reported low sensitivity (24\%) and high specificity $(95 \%)$ of the $2 \mathrm{PD}$ at the cutoff value of $5 \mathrm{~mm} .{ }^{(29)}$ The cutoff value was equal to the present study while the diagnostic values differed. However, among those published articles from 1984 to 1992, the gold standard of diagnosis and electrodiagnosis machine differed from that of the present.

In this study, 2PD and NCS were conducted on the same day. The physical examiner and electromyographer were blinded to each other's results. This study evaluated patients suspected of having CTS with few nonCTS patients for comparison. Thus, selection bias also affected NPV and PPV in this study. Additionally, a lack of test-retest reliability and interpersonal reliability might have posed an important limitation. The force of testing 2PD by single examiner might have been unstable.

\section{Conclusion}

Patients with symptoms of CTS, having 2PD test result $>4 \mathrm{~mm}$ of the first 3 digits had a high probability of CTS. The severity of CTS might not be determined by 2 PD test.

\section{References}

1. Robinson LR. Electrodiagnosis of carpal tunnel syndrome. Phys Med Rehabil Clin N Am 2007; 18: 733-46, vi.

2. Palmer KT, Harris EC, Coggon D. Carpal tunnel syndrome and its relation to occupation: a systematic literature review. Occup Med (Lond) 2007; 57: 57-66.

3. Preston DC SB. Electromyography and neuromuscular disorders, clinical electro physiologic correlation, 2nd ed. Pensylvania: Elsevier; 2005.

4. Herrmann DN, Logigian EL. Electrodiagnostic approach to the patient with suspected mononeuropathy of the upper extremity. Neurol Clin 2002; 20: 451-78, vii.

5. Nadler SF SS, Nadler JS. Cumulative trauma disorders. In: DeLisa JA GB, Walsh NE, editor. Physical medicine and rehabilitation: principles and practice. 4th ed. Philadelphia: Lippincott Williams \& Wilkins; 2005. p. 615-30.

6. Aroori S, Spence RAJ. Carpal tunnel syndrome. Ulster Med J 2008;77: 6-17.

7. Jablecki CK, Andary MT, So YT, Wilkins DE, Williams FH. Literature review of the usefulness of nerve conduction studies and electromyography for the evaluation of patients with carpal tunnel syndrome. AAEM Quality Assurance Committee. Muscle Nerve 1993; 16: 1392-414.

8. Kohara N. Clinical and electrophysiological findings in carpal tunnel syndrome. Brain Nerve 2007; 59: 1229-38.

9. Shooter D. Use of two-point discrimination as a nerve repair assessment tool: preliminary report. ANZ J Surg 2005; 75: 866-8. 
10. Tamburin S, Cacciatori C, Praitano ML, Cazzarolli C, Foscato C, Fiaschi A, et al. Median nerve small- and large-fiber damage in carpal tunnel syndrome: a quantitative sensory testing study. J Pain 2011; 12: 205-12.

11. Pipatyaokul R, Jianmongkol S, Kowsuwon W. Reliability of the compasses for measuring two-point discrimination and moving two-point discrimination test compared with the Disk-criminator. Srinagarind Med J 2006; 21: 57-66.

12. Marx RG, Hudak PL, Bombardier C, Graham B, Goldsmith C, Wright JG. The reliability of physical examination for carpal tunnel syndrome. J Hand Surg Br 1998; 23: 499502.

13. Magee DJ. Orthopedic Physical Assessment. London, United Kingdom: Elsevier Health Sciences; 5th ed. 2008.

14. Marlowe ES, Bonner FJ, Jr., Berkowitz AR. Correlation between two-point discrimination and median nerve sensory response. Muscle Nerve 1999; 22: 1196-200.

15. Braddom RL. Physical Medicine \& Rehabilitation. Philadelphia: Elsevier Saunders; 4th ed. 2011.

16. MacDermid JC, Doherty T. Clinical and electrodiagnostic testing of carpal tunnel syndrome: a narrative review. J Orthop Sports Phys Ther 2004; 34: 565-88.

17. MacDermid JC, Wessel J. Clinical diagnosis of carpal tunnel syndrome: a systematic review. J Hand Ther 2004; 17: 309-19.

18. Elfar JC, Yaseen Z, Stern PJ, Kiefhaber TR. Individual finger sensibility in carpal tunnel syndrome. J Hand Surg Am 2010; 35: 1807-12.

19. Kuhlman KA, Hennessey WJ. Sensitivity and specificity of carpal tunnel syndrome signs. Am J Phys Med Rehabil 1997; 76: 451-7.

20. Ziswiler HR, Reichenbach S, Vogelin E, Bachmann LM, Villiger PM, Juni P. Diagnostic value of sonography in patients with suspected carpal tunnel syndrome: a prospective study. Arthritis Rheum 2005; 52: 304-11.
21. Crosby PM, Dellon AL. Comparison of two-point discrimination testing devices. Microsurgery 1989; 10: 134-7.

22. Basiri K, Katirji B. Practical approach to electrodiagnosis of the carpal tunnel syndrome: A review. Adv Biomed Res 2015; 4: 50 .

23. Jablecki CK, Andary MT, Floeter MK, Miller RG, Quartly CA, Vennix MJ, et al. Practice parameter: Electrodiagnostic studies in carpal tunnel syndrome. Report of the American Association of Electrodiagnostic Medicine, American Academy of Neurology, and the American Academy of Physical Medicine and Rehabilitation. Neurology 2002; 58: 1589-92.

24. Werner RA, Andary M. Electrodiagnostic evaluation of carpal tunnel syndrome. Muscle Nerve 2011; 44: 597-607.

25. Borg K, Lindblom U. Diagnostic value of quantitative sensory testing (QST) in carpal tunnel syndrome. Acta Neurol Scand 1988; 78: 537-41.

26. Vorawanthanachai T, Wongtra-gnan N, Kovindha A. Correlation between static two-point discrimination test and nerve conduction study of ulnar nerve in patients with ulnar neuropathy at the elbow. J Thai Rehabil Med 2012; 22: 95-101.

27. Wolny T, Saulicz E, Linek P, Myśliwiec A. Two-point discrimination and kinesthetic sense disorders in productive age individuals with carpal tunnel syndrome. J Occup Health 2016; 58: 289-96.

28. Khanittanuphong P, Leelasamran W, Boonmeeprakob A. Diagnostic accuracy of provocative tests in the diagnosis of carpal tunnel syndrome. J Thai Rehabil Med 2011; 21: 56-62.

29. MacDermid JC, Wessel J. Clinical diagnosis of carpal tunnel syndrome: a systematic review. J Hand Ther 2004; 17: 309-19. 